\title{
Anti-inflammatory Activity of Methanolic Extract from Pistacia atlantica Desf. Leaves
}

\author{
Oukacha Amri ${ }^{1}$, Abderrahmane Zekhnini ${ }^{2 *}$, Abdellah Bouhaimi ${ }^{2}$, Saida Tahrouch ${ }^{1}$, Abdelhakim Hatimi ${ }^{1}$
}

\section{Oukacha Amri' ${ }^{1}$, Abderrah- mane Zekhnini ${ }^{*}$, Abdel- lah Bouhaimi², Saida- Tahrouch ${ }^{1}$, Abdelhakim Hatimi $^{1}$}

'Laboratoire de Biotechnologies Végétales, Faculté des Sciences, 80000 Agadir, MOROCCO.

2 Laboratoire des Systèmes Aquatiques, Faculté des Sciences, 80000 Agadir, MOROCCO.

\section{Correspondence}

\section{Abderrahmane Zekhnini}

Laboratoire des Systèmes Aquatiques, Faculté des Sciences, 80000 Agadir, MOROCCO

Tel: 00212528220957,

Fax: 00212528220100

E-mail: a.zekhnini@uiz.ac.ma

\section{History}

- Submission Date: 07-08-2017.

- Review completed: 11-09-2017;

- Accepted Date: 02-11-2017

DOI : 10.5530/pj.2018.1.14

Article Available online

http://www.phcogj.com/v10/i1

\section{Copyright}

(C) 2018 Phcog. Net. This is an openaccess article distributed under the terms of the Creative Commons Attribution 4.0 International license.

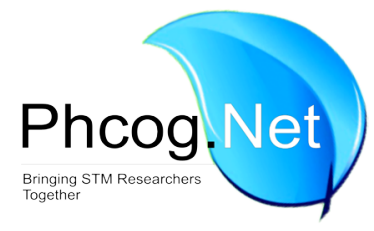

\begin{abstract}
Introduction: The extracts of the Pistacia species are known for their anti-inflammatory activity, including fruits and oil of $P$. atlantica. However, the inflammatory effect of the methanolic extract of $P$. atlantica leaves has not been studied. This work aimed at assessing the antiinflammatory and antioxidant activities of $P$. atlantica leaves extract in relation to phytochemical studies of flavonoids. Methods: The extract was obtained using sonication of leaves powder in $80 \%$ methanol. The analysis of phenolic compounds was carried out using thin-layer chromatography (TLC). The antioxidant activity was evaluated using DPPH, ABTS and FRAP assays. The anti-inflammatory activity was determined by the reduction of carrageenaninduced hind paw edema in mice. Results: The TLC revealed 3 glycosylated flavonoids and gallic acid derivatives. The flavonoids identified corresponded to rutin, quercetrin and other heterosides of quercetin, kaempferol and myricetin. Total phenolics and flavonoids contents were comparable for the male and female trees. The antioxidant activity did not show a significative difference between the two sexes, except for that evaluated by the FRAP assay which was significantly greater for the male tree leaves extract. The leaves extract permitted significative reduction of the edema at h3 and 6 in a dose-dependent manner (100 and $250 \mathrm{mg} / \mathrm{kg}$ ), while diclofenac used as control reduced the edema at $\mathrm{h} 1.5$. This difference could be explained by the pharmacokinetic and pharmacodynamic properties of diclofenac and $P$. atlantica leaves compounds. Conclusion: $P$. atlantica has a strong anti-inflammatory activity and constitutes a potential source for the development of new treatments. Key words: Antioxidant activity, Flavonoids, Methanolic extract, Plantar edema, TLC.
\end{abstract}

\section{INTRODUCTION}

Over the last decade, great progress has been made in understanding the physiopathology of inflammation and the involvement of free radicals in its pathogenesis. The reactive oxygen species (ROS) produced from the action of free radicals on molecular oxygen increase abnormally during inflammation, causing an imbalance between the oxidizing molecules and the antioxidant system of the body. This oxidative stress causes inflammatory cascades that damage the cellular components. ${ }^{1}$ The humoral and cellular mechanisms of inflammation are numerous and complex. They involve gene regulatory factors such as the nuclear factor-kappa B (NF- $\mathrm{B}$ ) and signaling substances synthesized by immune system cells such as cytokines and prostaglandins. ${ }^{2}$

Many factors may be at the origin of the inflammatory process; Infectious agents, ischemia, antigen-antibody interaction, thermal or physical shocks. ${ }^{3}$ Steroid drugs, nonsteroidal anti-inflammatory drugs (NSAIDs) and immunosuppressants, usually used for the relief of inflammatory diseases, require long-term treatment and their use is often associated with serious side effects such as bleeding gastrointestinal and peptic ulcers. ${ }^{4}$ This has led to the search for alternative treatments. In this regard, secondary metabolites of various medicinal plants have been shown to be effective in the treatment of inflammation and pain..$^{5}$ Among these plants, the species of Pistacia genus are of interest. Indeed, this genus includes 11 species that are widely distributed on the different continents of the terrestrial globe. They are found in temperate forests, tropical hardwoods and boreal conifers. ${ }^{6}$ P. atlantica is one of the most widespread wildlife species. It is the most characteristic plant of the arid and semi-arid zones of the northern part of Africa. ${ }^{7}$ In traditional medicine, $P$. atlantica is used for the treatment of pain and other conditions such as upper abdominal discomfort, dyspepsia and peptic ulcer. ${ }^{8}$ Several studies reported that the different parts of the plant as fruits, galls and oil, have biological effects including anti-inflammatory

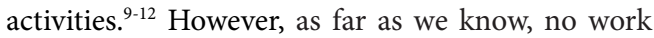
has been devoted to the study of the anti-inflammatory effect of the methanolic extract of $P$. atlantica leaves (MEPaL). Thus, this study aimed at assessing the anti-inflammatory activity of 
the MEPal using carrageenan-induced hind paw edema in mice, in relation to the flavonoid composition evaluated by both thin-layer chromatography (TLC) and chemical assays.

\section{MATERIALS AND METHODS}

\section{Preparation of the methanolic extract}

Leaves of male and female $P$. atlantica were collected from Tafilalt region in the south of Morocco. They were dried in the shade at $40^{\circ} \mathrm{C}$ and ground to a fine powder. Fifty $\mathrm{mg}$ of the fine powder were extracted with $1 \mathrm{ml}$ of methanol-water solvent (80/20; v/v). After sonication for $15 \mathrm{~min}$ and centrifugation at $12000 \mathrm{rpm}$ for $10 \mathrm{~min}$ at room temperature, the supernatant was recovered and kept at $4^{\circ} \mathrm{C}$.

\section{Phytochemical screening}

It was performed using standard procedures to highlight the secondary metabolites. Extraction and revelation of these compounds involve a set of solvents and developers: methanol for extracting flavonoids, alkaloids and tannins; chloroform for cyanogenic compounds and coumarin; petroleum ether for free quinones; hexane for terpenes; and water for saponins. The developers used for the revelation were: 2-aminoethyldiphenyl borate (Neu's reagent) $1 \%$ in methanol ${ }^{13}$ for flavonoids; Dragendorff reagents, Mayer and iodoplatinate for alkaloids revelation; ${ }^{14}$ iron chloride $\left(\mathrm{FeCl}_{3}\right)$ in $1 \%$ methanol for detecting tannins; ${ }^{15} 1 \%$ antimony trichloride in chloroformto reveal terpenes.

TLC was performed on a $10 \times 20 \mathrm{~cm}$ TLC sheets coated with $0.2 \mathrm{~mm}$ layers of silica gel N-HR/UV ${ }_{254}$ (Macherey-Nagel, Ref. 804023). After application of the extract and the standard solution $(5 \mu \mathrm{l})$ the sheet was developed in paper-lined all-glass previously left for a preconditioning in the developing chamber for at least $30 \mathrm{~min}$. The mobile phases used were: Ethyl acetate-Formic acid-Acetic acid (35\%) -Water (100:11:11:26, v/v/v/v); Acetic acid 2\%; Acetic acid 10\%; Ethyl acetate - MethanolWater (100-13.5-10) ; Ethyl acetate - Formic acid -Water (65-15-20); Ethyl acetate - Methanol-Formic acid-Water (100-13.5-2.5-10) ; TolueneEthyl acetate - Acetic acid (70-30-1). The visualization of the flavonoids and phenolic acids was achieved by spraying the sheets with $1 \%$ methanolic diphenylboryloxyethylamine (Neu's reagent) followed by $5 \%$ ethanolic polyethylene glycol 4000 .

The acidic hydrolysis, aiming to break $\mathrm{C}-\mathrm{O}-\mathrm{C}$ bonds involved in the glycosides, was conducted using chlorhydric acid $(2 \mathrm{~N})$. One g of leaves powder was homogenized with $80 \mathrm{~mL}$ of $2 \mathrm{~N} \mathrm{HCl}$ and the mixturewas placed in a water bath at $100{ }^{\circ} \mathrm{C}$ for $40 \mathrm{~min}$.

\section{Determination of total phenols content ${ }^{16}$}

To $25 \mu$ of plant extract were added $110 \mu$ of Folin-Ciocalteu solution. The mixture was stirred for $3 \mathrm{~min}$ and then $200 \mu \mathrm{l}$ of sodium carbonate $\left(\mathrm{Na}_{2} \mathrm{C}_{\mathrm{O} 3}\right)$ and $1.9 \mathrm{ml}$ of distilled water were added. After incubation for $30 \mathrm{~min}$ at $60^{\circ} \mathrm{C}$ in a water bath in the dark, the absorbance was measured at $750 \mathrm{~nm}$ (IC 6400 visible spectrophotometer). The calibration range was made using gallic acid as standard. The results were expressed in terms of $\mu$ g gallic acid equivalents (GAE)/mg of dry weight (DW).

\section{Determination of total flavonoids content ${ }^{17}$}

To $600 \mu \mathrm{l}$ of plant extract were added $300 \mu \mathrm{l}$ of $\mathrm{AlCl}_{3}$. The mixture was incubated for $30 \mathrm{~min}$ at room temperature. Then, the absorbance was measured at $430 \mathrm{~nm}$. Rutin was used as standard. The concentrations were expressed in terms of $\mu \mathrm{g}$ rutin equivalents/mg of dry weight ( $\mu \mathrm{g} \mathrm{RE} / \mathrm{mg}$ of DW).

\section{Determination of antioxidant activity}

The evaluation of the antioxidant activity was carried out by free radical scavenging method (DPPH and ABTS) and ferric reducing antioxidant power (FRAP).

\section{DPPH scavenging activity}

The antiradical power of substances was measured by the decrease of absorption of DPPH (1,1-Diphenyl-2- picrylhydrazyl). ${ }^{18}$ To $950 \mu \mathrm{l}$ of a methanol solution of DPPH $(0.1 \mathrm{mM})$ were added to $50 \mu \mathrm{l}$ of the plant extract. After $30 \mathrm{~min}$, the absorbance of the mixture was measured at $517 \mathrm{~nm}$. The ability to scavenge DPPH radical was calculated using the following formula:

$$
\text { \% Inhibition of DPPH }=\frac{\left(A_{c}-A_{s}\right)}{A_{c}} \times 100
$$

Ac: absorbance of control

As: absorbance of sample

\section{ABTS scavenging activity}

The technique is based on the scavenging of ABTS ${ }^{++}$[(3-ethyl benzothiazoline 6-sulfonic acid) diammonium salt] radical cation which was generated by mixing solutions of ABTS $(7 \mathrm{mmol} / \mathrm{L})$ and potassium persulfate $(2.45 \mathrm{mmol} / \mathrm{L}) .{ }^{19}$ The mixture was then incubated in the dark at room temperature for $16 \mathrm{~h}$. The product was diluted for optimal absorbance of 0.7 at $734 \mathrm{~nm}$. The decolorization of the ABTS ${ }^{*+}$ solution by 100 $\mu \mathrm{g} / \mathrm{mL}$ of the test sample or reference compound (Trolox) was monitored by a decrease in absorption at $734 \mathrm{~nm}$ during $30 \mathrm{~min}$. The antioxidant activity expressed in $\mu \mathrm{M}$ trolox equivalent antioxidant capacity (TEAC)/ mg dry weight (DW).

\section{Ferric reducing antioxidant power (FRAP)}

The method is based on reduction of ferric tripyridyltriazine ( $\left.\mathrm{Fe}_{3}-\mathrm{TPTZ}\right)$ to ferrous complex tripyridyltriazine $\left(\mathrm{Fe}_{2}-\mathrm{TPTZ}\right)$ by an antioxidant in acidic $\mathrm{pH}$. The ferrous Fe (II) complex -TPTZ develops a blue color with maximal absorbance at $593 \mathrm{~nm}$. The methodology of Benzie and Strain ${ }^{20}$ was used. FRAP mixture consists of 10 parts of acetate buffer solution $(300 \mathrm{mM})$ at $\mathrm{pH} \mathrm{3.6,1}$ volume of $10 \mathrm{mmol} / \mathrm{l}$ 2,4,6-tripyridyl-s-triazine (TPTZ) in $40 \mathrm{mmol} / 1 \mathrm{HCl}$ and 1 volumes of a solution of $\mathrm{FeCl} 36 \mathrm{H} 2 \mathrm{O}$ $(20 \mathrm{mM})$. To $2 \mathrm{ml}$ of the FRAP mixture were added $10 \mu \mathrm{l}$ of the plant extract. After incubation of $15 \mathrm{~min}$ at room temperature, the absorbance was measured at $593 \mathrm{~nm}$. The calibration range was prepared with Trolox. Results are expressed as $\mu \mathrm{mol}$ Trolox equivalent antioxidant capacities (TEAC)/mg DW.

\section{Carrageenan-induced hind paw edema}

Adult albino mice were obtained from "Office National de Securité Sanitaire des Aliments" (ONSSA), Agadir-Morocco, and shifted to the animal house of the Faculty of Sciences (Agadir-Morocco) one week earlier. Animals were kept on a 12 -h light/12-h dark cycle at $22 \pm 2{ }^{\circ} \mathrm{C}$, and had free access to pallet chow and water. All the procedures were in strict accordance with "Guidelines for the care and use of laboratory animals" (Ministry of Agriculture, Law No. 28-7, Decree No. 2-10-473). Mice weighing 25-35 g were fasted for $24 \mathrm{~h}$ prior to the experiment and deprived of water only during the experiment. According to the method of Winter et al., ${ }^{21}$ animals were subjected to sub plantar injection of 0.1 $\mathrm{mL}$ of $\lambda$-carrageenan ( $1 \%$ in $\mathrm{NaCl} 0.9 \%$ ) into the right hind paw and were divided randomly into allocated groups $(n=6)$. Then, they were subjected to a gavage with the following solutions; Group I: sterile saline $0.9 \% \mathrm{NaCl}$ at $10 \mathrm{~mL} / \mathrm{kg}$; Group II: sodium diclofenac at $50 \mathrm{mg} / \mathrm{kg}$ as reference drug, Group III: extract of $P$. atlantica leaves at $100 \mathrm{mg} / \mathrm{kg}$; Group IV: the same extract at $250 \mathrm{mg} / \mathrm{kg}$. P. atlantica extract and Diclofenac, both dissolved in $0.9 \% \mathrm{NaCl}$, were administered by oral dose $1 \mathrm{~h}$ following carrageenan injection. The MEPaL was first evaporated under vacuum at room temperature to remove the methanol, and then the deposit was solubilized in a $0.9 \% \mathrm{NaCl}$ solution. 
The circumference of paw was measured at h1.5, 3 and 6 after carrageenan injection. Increases in the linear circumference of the right hind paw were taken as an indicator of paw edema. Percentage increase in edema $(\% \mathrm{IO})$ was estimated in terms of the difference in the zero time $\left(\mathrm{C}_{0}\right)$ linear circumference of the injected right hind paw, and its linear circumference at time $\mathrm{t}\left(\mathrm{C}_{\mathrm{t}}\right)$ :

$$
\% \mathrm{IO}=\frac{\left(\mathrm{C}_{\mathrm{t}}-\mathrm{C}_{0}\right)}{\mathrm{C}_{0}} \times 100
$$

Percentage inhibition of the inflammatory reaction produced by carrageenan was calculated following formula:

$$
\% \text { Inhibition }=\frac{\left(\mathrm{IO}_{c}-\mathrm{IO}_{\mathrm{t}}\right)}{\mathrm{IO}_{\mathrm{c}}} \times 100
$$

Where $\mathrm{IO}_{c}$ and $\mathrm{IO}_{\mathrm{t}}$ represented the mean increase in paw circumference in control and treated groups, respectively.

\section{Statistical analysis}

Statistica 6 software was used for statistical analysis. Differences between groups were determined using analysis of variance (ANOVA) followed by Student Newman-Keuls method for post hoc analysis.

\section{RESULTS AND DISCUSSION}

Table 1 and Figure 1 show the screening and the TLC profile of MEPaL respectively. Figures 2 and 3 correspond to the chromatographic analysis following an acid hydrolysis and an addition of flavonoid standards, respectively. The results showed the presence of flavonoids, terpenes, tannins, coumarin tannins, and the absence of alkaloids and saponins. In addition of gallic acid derivatives, 3 glycosylated flavonoids were identified. The compounds corresponded to rutin, quercetrin and heterosides of quercetin, kaempferol and myricetin (Figure 4).

The content of polyphenols and flavonoids is reported in Table 2. The results showed a total polyphenol content of $65.47 \pm 6.80$ and $58.82 \pm$ $3.43 \mathrm{mg} \mathrm{GAE} / \mathrm{g}$ DW in the male and female trees respectively. The level of flavonoids was $110.62 \pm 15.79$ and $100.10 \pm 4.50 \mathrm{~g} \mathrm{RE} / \mathrm{g}$ DW for the 2 sexes respectively. However, the variations noted in the 2 sexes were not significantly different. The values obtained for total phenolics compounds are comparable to those previously reported for the same species. ${ }^{22,23}$ For the total flavonoids content, lower values have been reported for P. atlantica from the south-west of Morocco and Iran. ${ }^{22,24}$ This could be explained by different factors as the genetic variability of the plant and the effect of the climat which is more tempered in the south of Morocco thanks to the oceanic influence.

\begin{tabular}{|c|c|c|c|}
\hline \multicolumn{2}{|c|}{ Secondary metabolites classes } & Female & Male \\
\hline \multicolumn{2}{|l|}{ Gallic tanins } & + & + \\
\hline \multicolumn{2}{|l|}{ Saponins } & - & - \\
\hline \multicolumn{2}{|l|}{ Terpens } & + & + \\
\hline \multicolumn{2}{|l|}{ Coumarines } & + & + \\
\hline \multirow[t]{2}{*}{ Flavonoïdes } & Aglycone flavonoids & + & + \\
\hline & Draggendorf test & - & - \\
\hline \multirow[t]{2}{*}{ Alcaloïdes } & Iodoplatinate test & - & - \\
\hline & Mayer test & - & - \\
\hline
\end{tabular}

Table 1: Screening of secondary metabolites in P. atlantica leaves extract

$+:$ presence, $-:$ absence

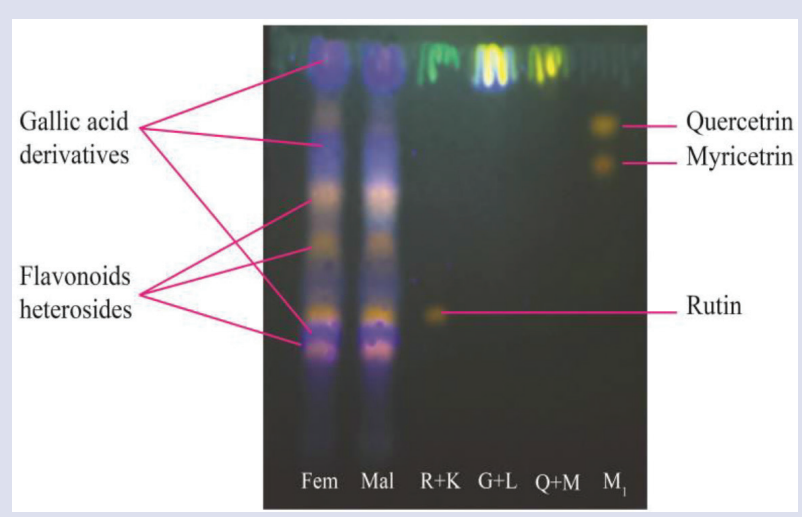

Figure 1: Chromatographic profile of $P$. atlantica leaves extracts Standard mixtures: R+K: Rutin + Kaempferol: G+L: Gallic acid + Luteolin;

Q+M : Quercitin + Myricetin; $M_{1}$ : Myricetrin + Quercitrin

Table 2: Total phenolics and flavonoids in P. atlantica leaves extract

\begin{tabular}{ccc}
\hline Extracts & Total phenolics (mg GAE /g DW) & Flavonoids (mg ER/g DW) \\
\hline Female & $58.82 \pm 3.43^{\mathrm{a}}$ & $100.10 \pm 4.50^{\mathrm{a}}$ \\
Male & $65.47 \pm 6.80^{\mathrm{a}}$ & $110.62 \pm 15.79^{\mathrm{a}}$ \\
\hline
\end{tabular}

Values are expressed in mean \pm SEM. Means in each column followed by the same letter are not significantly different $(\mathrm{P}<0.05)$

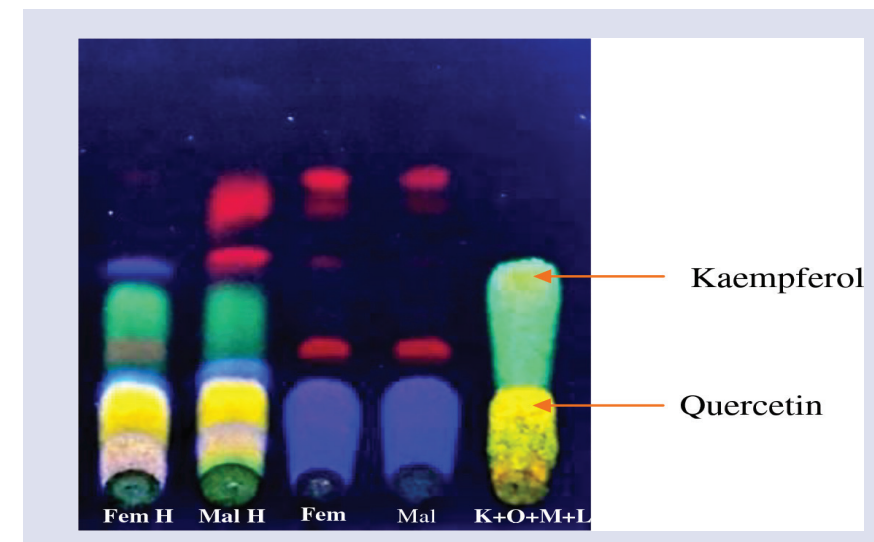

Figure 2: Chromatographic profile of hydrolyzed P. atlantican leaves extract

Fem: Female; Mal: Male; $\mathrm{H}$ : Hydrolyzed extract, $\mathrm{K}+\mathrm{Q}+\mathrm{M}+\mathrm{L}$ :

kaempferol + quercetin + myricetin + luteolin as standard mixture

Table 3 shows the antioxidant activity evaluated by the three techniques. The $\mathrm{IC}_{50}$ of the DPPH radical scavenging was $162.6 \pm 17.26$ and $135.6 \pm$ $16.07 \mu \mathrm{g} / \mathrm{ml}$ respectively for the male and female plants. For the ABTS test, the male and female trees exhibited values of $1633.08 \pm 33.29$ and $1448.06 \pm 25.41 \mu \mathrm{M}$ TEAC/mg DW respectively. Whether for the DPPH test or the ABTS test, differences between the male and female trees were not significant. With respect to FRAP, the MEPaLs of male and female trees recorded significantly different values $(86.64 \pm 3.79$ and $66.55 \pm$ $4.52 \mu \mathrm{M}$ TEAC/mg DW respectively). The literature reports that the antioxidant activity of plant extracts depends on both the nature of the 
Table 3: Antioxidant activitie of $P$. atlantica leaves extract assessed by DPPH, ABTS and FRAP methods

\begin{tabular}{|c|c|c|c|c|c|c|c|c|c|}
\hline \multirow[t]{2}{*}{ Activity } & \multicolumn{7}{|c|}{ DPPH (\%) } & \multirow[b]{2}{*}{$\begin{array}{c}\text { ABTS ( } \mu \mathrm{M} \text { TEAC/ } \\
\text { mg DW) }\end{array}$} & \multirow[b]{2}{*}{$\begin{array}{c}\text { FRAP }(\mu \mathrm{M} \\
\text { TEAC/mg DW) }\end{array}$} \\
\hline & $\begin{array}{c}62,50 \mu \mathrm{g} / \\
\mathrm{ml}\end{array}$ & $156,25 \mu \mathrm{g} / \mathrm{ml}$ & $\begin{array}{c}312,50 \mu \mathrm{g} / \\
\mathrm{ml}\end{array}$ & $\begin{array}{c}468,75 \mu \mathrm{g} / \\
\mathrm{ml}\end{array}$ & $\begin{array}{c}562,50 \mu \mathrm{g} / \\
\mathrm{ml}\end{array}$ & $\begin{array}{c}625,00 \mu \mathrm{g} / \\
\mathrm{ml}\end{array}$ & $\mathrm{IC}_{50}(\mu \mathrm{g} / \mathrm{ml})$ & & \\
\hline Femelle & $31.91 \pm 0.57$ & $53.92 \pm 1.64$ & $72.97 \pm 0.58$ & $80.02 \pm 0.57$ & $82.53 \pm 0.68$ & $84.80 \pm 0.65$ & $135.6 \pm 16.07^{\mathrm{a}}$ & $1448.06 \pm 25.41^{\mathrm{a}}$ & $66.55 \pm 4.52^{\mathrm{b}}$ \\
\hline Male & $17.62 \pm 1.65$ & $41.21 \pm 1.15$ & $64.96 \pm 1.73$ & $76.16 \pm 1.63$ & $78.30 \pm 1.42$ & $78.88 \pm 1.62$ & $162.6 \pm 17.26^{\mathrm{a}}$ & $1633.08 \pm 33.29^{\mathrm{a}}$ & $86.64 \pm 3.79^{\mathrm{a}}$ \\
\hline
\end{tabular}

Values are expressed in mean \pm SEM. Means in each column followed by different letters are significantly different $(\mathrm{P}<0.05)$

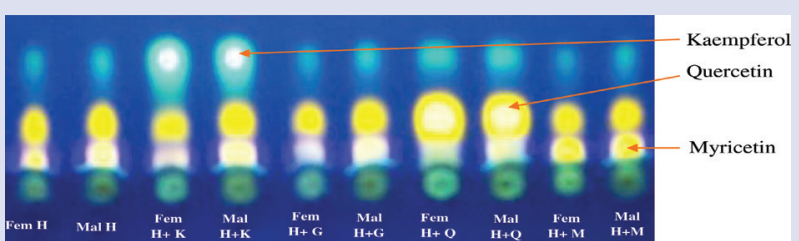

Figure 3: Chromatographic profile of hydrolyzed $P$. atlantica leaves extract with addition of Standards

Fem: Female; Mal: Male; H: Hydrolysed; K: Kaempferol; G: Gallic acid; Q: Quercetin, M: Myricetin

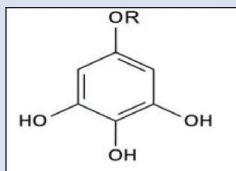<smiles></smiles>

Myricetin derivatives
Gallic acid ester derivatives

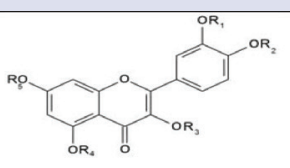

Quercetin derivatives

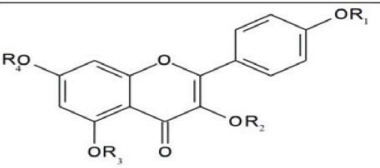

Kaempferol derivatives
Figure 4: Phenolic compounds identified in P. atlantica leaves extract<smiles>O=c1c(O)c(-c2ccc(O)c(O)c2)oc2cccc(O)c12</smiles>

Figure 5: Structure of aglycone flavonoid.

In red: ortho-dihydroxy structure in the B ring. In blue: double bond in conjugation with a 4-oxo function in the $C$ ring. In green: hydroxyl groups at positions 3 and 5 .

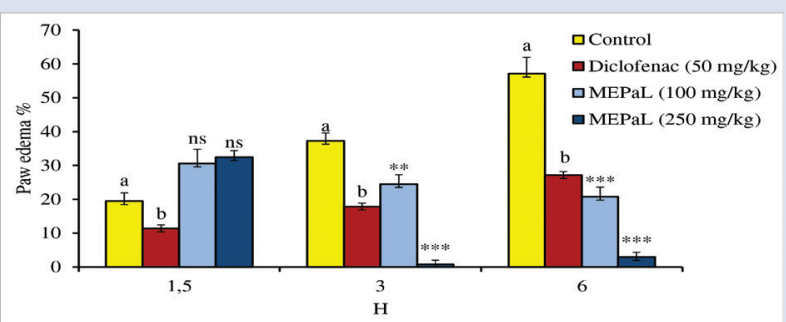

Figure 6: Reduction of paw edema by oral administration of Diclofenac and methanolic extract of $P$. atlantica leaves (MEPaL) (100 and $250 \mathrm{mg} / \mathrm{kg}$ ) at 1.5, 3 and $6 \mathrm{~h}$ after the induction of edema. Results are expressed as mean $\pm \operatorname{SEM}(n=6)$.

Diclofenac group versus control group: results with same letters are not significantly different at $P=0.05$. MEPaL group versus diclofenac group: ${ }^{* *}$ significant difference at $p<0.01{ }^{* * *}$ significant difference at $p<0.001$

test and the phenolic compounds. ${ }^{25}$ For example, quercetin showed very low antioxidant activity in the FRAP test but very high activity in the DPPH and ABTS assays. ${ }^{26}$ Indeed, polyphenols are compounds which have more than one hydroxyl group attached to one or more benzene rings. They are usually encountered as esters or glycosides rather than as free compounds. Then, the antioxidant activity of the polyphenols depends on the arrangement and the number of hydroxyl groups in the phenolic rings and their connections with the saccharides. Polyphenols could act as reducing initiators, chelating agents or by the prevention of oxidative reactions caused by active singlet oxygen..$^{27,28}$ For our study, the antioxidant activity could be explained by the presence of gallic acid and its derivatives and the flavonoids rutin, quercetrin and quercetin heterosides. Indeed, the glycosides of quercetin, despite the presence of osides, contribute to the antioxidant power thanks to the ortho-dihydroxy structure in the $\mathrm{B}$ ring, and the double bond in conjunction with the 4-oxo function in the $\mathrm{C}$ ring (Figure 5). As a result, the antioxidant activity of the aglycone flavonols is relatively high. Finally, kaempferol possesses a lower activity due to the presence of a single hydroxyl in the B ring. ${ }^{29-31}$ These data make it possible to conclude that the antioxidant activity recorded in our work results from the synergy of the various phenolic compounds, even with other non-phenolic antioxidants. ${ }^{32,33}$

The results of the anti-inflammatory activity are shown in Figure 6. The inflammation caused by carrageenan increased with time and reached a maximum after $6 \mathrm{~h}(57.16 \pm 4.82 \%)$. Administration of Diclofenac (100 mg/kg body weight) significantly reduced plantar edema at 1.5, 3 and $6 \mathrm{~h}$ following the carrageenan administration (44.31\%, 52.09\% and $52.48 \%$ respectively). Administration of MEPaL decreased plantar edema significantly later, starting at h 3 (34.28 and 97.88\%) and 6 (44.31 and $92.02 \%$ at doses of $100 \mathrm{mg} / \mathrm{kg}$ and $250 \mathrm{mg} / \mathrm{kg}$ body weight respectively). However, the anti-inflammatory effect obtained with the extract was more 
pronounced in comparison to Diclofenac. The rapid anti-inflammatory effect of Diclofenac is due to its pharmacokinetic properties represented by a $1 \mathrm{~h}$ Tmax and a bioavailability of $65 \%$ with oral administration. ${ }^{34}$ The later action of the MEPaL could be explained both by the pharmacokinetic and pharmacodynamic behaviour of the active secondary metabolites. Indeed, the digestion and absorption of flavonoids are slow processes especially for glycosylated forms because of the resistance of the osidic bonds resulting in decrease of bioavailability. ${ }^{35}$ On the pharmacodynamic level, the inflammatory process is complex and involves several cell signalling pathways in addition to the free radicals production which is responsible for tissue degeneration. One of the important mechanisms is an inhibition of eicosanoid-generating enzymes including phospholipase A2, cyclooxygenases (1 and 2), lipoxygenases and nitric oxide synthase (NOS), thereby reducing the concentrations of prostanoids and leukotrienes. ${ }^{36-39}$ In addition, flavonoids may modulate the expression of enzymes involved in inflammation and pro-inflammatory molecules by inhibiting transcription factors, such as NF- $\kappa$ B. As example, kaempferol may modulate NF- $\kappa \mathrm{B}$ signal pathways during inflammation and alter the expression of genes involved in the inflammatory process. ${ }^{40,41}$ In fact, the chromatographic analysis of MEPaL showed the presence of rutin and derivatives of quercetin, myricetin, kaempferol and gallic acid. The literature reported that rutin exerts intestinal anti-inflammatory effects in experimental models of colitis ${ }^{42}$ and methyl gallate, one of the main compounds of the active fraction of the methanolic extract of the same family of Anacardiacceae, Lithrea molleoides, would explain the antiinflammatory activity observed in the model of ear edema. ${ }^{43}$ Similarly, quercetin has been described as anti-inflammatory in several study mod$\mathrm{els}^{44}$ and kaempferol reported as an effective compound against inflammation..$^{45}$ These data make it possible to attribute the anti-inflammatory activity of the MEPaL to the presence of gallic acid derivatives and flavonoids such as the derivatives of quercetin, myricetin and kaempferol. However, further investigations should be carried out to determine the structure and content of $P$. atlantica glycosylated flavonoids.

\section{CONCLUSION}

Our study identified rutin, gallic acid derivatives and heterosids of quercetin, myricetin and kaempferol as flavonoids of $P$. atlantica leaves. The results showed that polyphenols and flavonoides contents were comparable in male and female trees. The same was true for the antioxidant activity except for the FRAP test which showed a greater activity in the male tree. The extract exhibited a strong anti-inflammatory activity which was expressed 3 and $6 \mathrm{~h}$ after the induction of the edema by injection of carageenan. These results allow us to conclude that $P$. atlantica leaves have potential for the development of new treatment against inflammatory conditions.

\section{ACKNOWLEDGEMENT}

The authors are thankful to «Office National de Sécurité Sanitaire des Aliments» (ONSSA), which graciously provided the mice for the experiment.

\section{CONFLICT OF INTEREST}

There is no conflict of interest.

\section{ABREVIATIONS USED}

ABTS: 2,2'-azino-bis(3-ethylbenzothiazoline-6-sulphonic acid); DPPH: 2,2-diphenyl-1picrylhydrazyle; FRAP: Ferric reducing antioxidant power; iNOS: Inducible nitric oxide synthase; MEPaL: Metanolic extract of Pistacia atlantica leaves; NF-kB: Nuclear factor-kappa B; NSAIDs: Nonsteroidal anti-inflammatory drugs.

\section{REFERENCES}

1. Seril DN, Liao J, Yang G-Y, Yang CS. Oxidative stress and ulcerative colitis-associated carcinogenesis: studies in humans and animal models. Carcinogenesis. 2003;24(3):353-62.

2. Ahmed AU. An overview of inflammation: mechanism and consequences Frontiers in Biology. 2011;6(4):274

3. Osadebe PO, Okoye FBC. Anti-inflammatory effects of crude methanolic extract and fractions of Alchornea cordifolia leaves. Journal of Ethnopharmacology. 2003;89(1):19-24.

4. Corley DA, Kerlikowske K, Verma R, Buffler P. Protective association of aspirin/ NSAIDs and esophageal cancer: a systematic review and meta-analysis. Gastroenterology. 2003;124(1):47-56.

5. Sheir Z, Nasr AA, Massoud A, Salama O, Badra GA, El-Shennawy H, et al. A safe, effective, herbal antischistosomal therapy derived from myrrh. The American Journal of Tropical Medicine and Hygiene. 2001;65(6):700-4.

6. Lévêque C, Mounolou J. Biodiversité, Dynamique biologique et conservation translated into English by Vivien Reuter (2003) as Biodiversity. Chichester: John Wiley. 2001

7. Fennane M, Ibn-Tattou M. Flore pratique du Maroc. Vol. 2. Angiospermae (Leguminosae-Lentibulariaceae): Inst. Sci. 2007.

8. Bozorgi M, Memariani Z, Mobli M, Salehi-Surmaghi MH, Shams-Ardekani MR, Rahimi R. Five Pistacia species ( $P$. vera, P. atlantica, P. terebinthus, P. khinjuk and P. lentiscus): A Review of Their Traditional Uses, Phyto chemistry, and Pharmacology. The Scientific World Journal. 2013;2013:33.

9. Bahmani M, Saki K, Asadbeygi M, Adineh A, Saberianpour S, Rafieian-Kopaei M, et al. The effects of nutritional and medicinal mastic herb (Pistacia atlantica). Journal of Chemical and Pharmaceutical Research. 2015;7(1):646-53.

10. Heidarian E, Jafari-Dehkordi E, Valipour P, Ghatreh-Samani K, Ashrafi-Eshkaftaki L. Nephroprotective and Anti-Inflammatory Effects of Pistacia atlantica Leaf Hydroethanolic Extract Against Gentamicin-Induced Nephrotoxicity in Rats. Journal of Dietary Supplements. 2017;14(5):489-502.

11. Minaiyan M, Karimi F, Ghannadi A. Anti-inflammatory effect of Pistacia atlantica subsp. kurdica volatile oil and gum on acetic acid-induced acute colitis in rat. Research Journal of Pharmacognosy. 2015;2(2):1-12.

12. Tanideh N, Masoumi S, Hosseinzadeh M, Safarpour AR, Erjaee H, Koohi-Hosseinabadi O, et al. Healing Effect of Pistacia atlantica Fruit Oil Extract in Acetic AcidInduced Colitis in Rats. Iranian Journal of Medical Sciences. 2014;39(6):522-8.

13. Neu R. A new reagent for differentiating and determining flavones on paper chromatograms. Naturwissenschaften. 1956;43(82):10-07.

14. Randerath K. Chromatographie sur couches minces: trad. de I'allemand par nguyen-dang-tam. 2e ed. rev. et augm: Gauthier-Villars. 1971.

15. Andary C. Contribution à l'étude botanique, chimique et pharmacodynamique d'Orobanche rapum-genistae Thuill(Orobanchacées). 1975.

16. Singleton V, Rossi JA. Colorimetry of total phenolics with phosphomolybdicphosphotungstic acid reagents. American journal of Enology and Viticulture. 1965;16(3):144-58.

17. Jay M, Gonnet J-F, Wollenweber E, Voirin B. Sur I'analyse qualitative des aglycones flavoniques dans une optique chimiotaxinomique. Phyto chemistry. 1975;14(7):1605-12

18. Masuda T, Yonemori S, OyamaY, Takeda Y, Tanaka T, Andoh T, et al. Evaluation of the Antioxidant Activity of Environmental Plants: Activity of the Leaf Extracts from Seashore Plants. Journal of Agricultural and Food Chemistry. 1999;47(4):1749-54.

19. Re R, Pellegrini N, Proteggente A, Pannala A, Yang M, Rice-Evans C. Antioxidant activity applying an improved ABTS radical cation decolorization assay. Free Radical Biology and Medicine. 1999;26(9-10):1231-7.

20. Benzie IFF, Strain JJ. The Ferric Reducing Ability of Plasma (FRAP) as a Measure of "Antioxidant Power": The FRAP Assay. Analytical Biochemistry. 1996;239(1):70-6.

21. Winter CA, Risley EA, Nuss GW. Carrageenin-Induced Edema in Hind Paw of the Rat as an Assay for Anti-inflammatory Drugs. Experimental Biology and Medicine. 1962;111(3):544-7.

22. Amri O, Elguiche R, Tahrouch S, Zekhnini A, Hatimi A. Antifungal and antioxidant activities of some aromatic and medicinal plants from the southwest of Morocco. Journal of Chemical and Pharmaceutical Research. 2015;7(7):672-8.

23. Malekzadeh P, Hatamnia AA, Nourollahi K. Total phenolic content and antioxidant activity of fruit and leaf of Bene (Pistacia atlantica subsp. Kurdica) in Ilam province. Iranian Journal of Plant Physiology. 2015;6:1543-9.

24. Hatamnia AA, Rostamzad A, Hosseini M, Abbaspour N, Darvishzadeh $R$ Malekzadeh $\mathrm{P}$, et al. Antioxidant capacity and phenolic composition of leaves from 10 Bene (Pistacia atlantica subsp. kurdica) genotypes. Natural Product Research. 2016;30(5):600-4.

25. Pellegrini N, Serafini M, Colombi B, Del Rio D, Salvatore S, Bianchi M, et al. Total Antioxidant Capacity of Plant Foods, Beverages and Oils Consumed in Italy Assessed by Three Different in vitro Assays. The Journal of Nutrition. 2003;133(9):2812-9

26. Lee L-S, Choi E-J, Kim C-H, Sung J-M, Kim Y-B, Seo D-H, et al. Contribution of flavonoids to the antioxidant properties of common and Tartary buckwheat. Journal of Cereal Science. 2016;68:181-6. 
27. Mitek M, Gasik A. Polyphenols in food. Antioxidant properties. Przemysl Spozywczy. 2007;9:36.

28. Rosicka-Kaczmarek J. Polyphenols as natural anti-oxidants in food. Przegl Piekar Cukier. 2004;6:12-6.

29. Lien EJ, Ren S, Bui HH, Wang R. Quantitative structure-activity relationship analysis of phenolic antioxidants. Free Radical Biology and Medicine. 1999;26(34):285-94.

30. Rice-Evans CA, Miller NJ, Paganga G. Structure-antioxidant activity relationships of flavonoids and phenolic acids. Free Radical Biology and Medicine. 1996;20(7):933-56

31. Soobrattee MA, Neergheen VS, Luximon-Ramma A, Aruoma OI, Bahorun T. Phenolics as potential antioxidant therapeutic agents: Mechanism and actions. Mutation Research/Fundamental and Molecular Mechanisms of Mutagenesis. 2005;579(1-2):200-13

32. El-Sayed MM, Abdel-Hameed E-SS, Ahmed WS, EI-Wakil EA. Non-phenolic antioxidant compounds from Buddleja asiatica. Zeitschrift für Naturforschung C. 2008;63(7-8):483-91.

33. Foti MC, Amorati R. Non-phenolic radical-trapping antioxidants. Journal of Pharmacy and Pharmacology. 2009;61(11):1435-48

34. Hinz B, Chevts J, Renner B, Wuttke H, Rau T, Schmidt A, et al. Bioavailability of diclofenac potassium at low doses. British Journal of Clinical Pharmacology. 2005;59(1):80-4

35. Graefe EU, Wittig J, Mueller S, Riethling A-K, Uehleke B, Drewelow B, et al. Pharmacokinetics and Bioavailability of Quercetin Glycosides in Humans. The Journal of Clinical Pharmacology. 2001;41(5):492-9.

36. González-Gallego J, Sánchez-Campos S, Tunon M. Anti-inflammatory properties of dietary flavonoids. Nutricion Hospital aria. 2007;22(3)
37. Kim HP, Son KH, Chang HW, Kang SS. Anti-inflammatory Plant Flavonoids and Cellular Action Mechanisms. Journal of Pharmacological Sciences. 2004;96(3):229-45.

38. Swanson H. Flavonoids and the Inflammatory Response.Flavonoids, Inflammation and Cancer: world scientific; 2015.p.59-104.

39. Yoon JH, Baek SJ. Molecular Targets of Dietary Polyphenols with Anti-inflammatory Properties. Yonsei Med J. 2005;46(5):585-96.

40. Hämäläinen M, Nieminen R, Vuorela P, Heinonen M, Moilanen E. Anti-Inflammatory Effects of Flavonoids: Genistein, Kaempferol, Quercetin, and Daidzein Inhibit STAT-1 and NF-kB Activations, Whereas Flavone, Isorhamnetin, Naringenin, and Pelargonidin Inhibit only NF-kB Activation along with Their Inhibitory Effect on iNOS Expression and NO Production in Activated Macrophages. Mediators of Inflammation. 2007;2007:10.

41. Gupta SC, Tyagi AK, Deshmukh-Taskar P, Hinojosa M, Prasad S, Aggarwal BB Downregulation of tumor necrosis factor and other proinflammatory biomarkers by polyphenols. Archives of Biochemistry and Biophysics. 2014;559:91-9

42. Mascaraque C, Aranda C, Ocon B, Monte MJ, Suarez MD, Zarzuelo A, et al Rutin has intestinal anti-inflammatory effects in the CD4+CD62 L+T cell transfer model of colitis. Pharmacological Res. 2014;90:48-57.

43. Gorzalczany S, López P, Acevedo C, Ferraro G. Anti-inflammatory effect of Lithrea molleoides extracts and isolated active compounds. Journal of Ethnopharmacology.2011;133(3):994-8.

44. Li Y, Yao J, Han C, Yang J, Chaudhry M, Wang S, et al. Quercetin, Inflammation and Immunity. Nutrients. 2016;8(3):167.

45. Devi KP, Malar DS, Nabavi SF, Sureda A, Xiao J, Nabavi SM, et al. Kaempfero and inflammation: From chemistry to medicine. Pharmacological Research. 2015;99:1-10

\section{GRAPHICAL ABSTRACT}

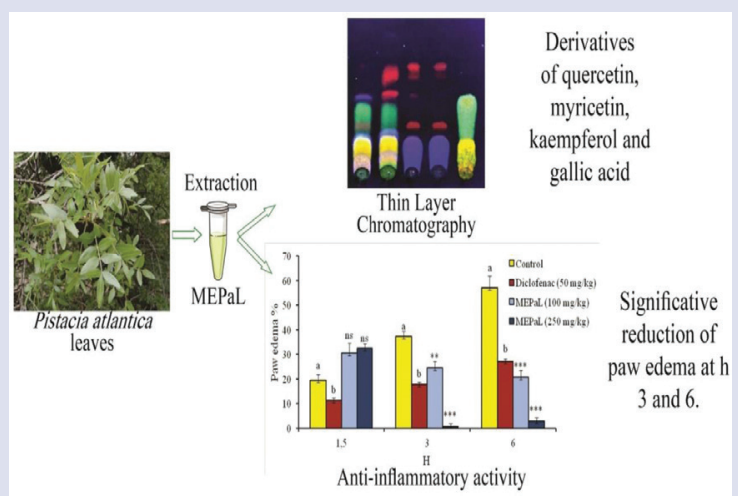

\section{SUMMARY}

- $\quad$ This paper reported an important anti-inflammatory activitie of methanolic extract of Pistacia atlantica leaves in mice plantar edema model.

- The flavonoids identified were rutin, quercetrin and heterosides of quercetin, kaempferol and myricetin.

- These compounds are known for their anti-inflammatory properties and may explain the results obtained in the experiment.

\section{ABOUT AUTHORS}

Oukacha Amri: Is currently preparing his PhD in Phytochemistry, at Ibn Zohr University, with a focus on the biological activities of plants from Morocco.

Abderrahmane Zekhnini: Is a Professor and researcher in Environment, Food sciences and Pharmacology at Ibn Zohr University, Agadir, Morocco.

Abdellah Bouhaimi: Is a Professor and Researcher in Environment and Physiology at Ibn Zohr University, Agadir, Morocco.

Saida Tahrouch: Is a Professor and researcher in Phytochemistry at Ibn Zohr University, Agadir, Morocco. Her works are focused on natural compounds as polyphenols particulary flavonoids in plants from Morocco.

Abdelhakim Hatimi: Is a Professor and Head of Laboratory of Plants Biotechnologies at Ibn Zohr University, with skills in Microbiology and Phytochemistry.

Cite this article: Amri O, Zekhnini A, Bouhaimi A, Tahrouch S, Hatimi A, Anti-inflammatory activity of methanolic extract from Pistacia atlantica Desf. leaves. Pharmacog J. 2018;10(1):71-6. 